\title{
Theoretical and Experimental Aspects of the Corrosivity of Simulated Soil Solutions
}

\author{
Rodrigo Antunes de Sena, Ivan Napoleão Bastos, and Gustavo Mendes Platt \\ Polytechnic Institute, Rio de Janeiro State University, Rua Bonfim 25, 28.625-570 Nova Friburgo, RJ, Brazil \\ Correspondence should be addressed to Ivan Napoleão Bastos, inbastos@iprj.uerj.br
}

Received 8 October 2012; Accepted 14 November 2012

Academic Editors: J. A. A. González and M. E. R. Shanahan

Copyright ( $) 2012$ Rodrigo Antunes de Sena et al. This is an open access article distributed under the Creative Commons Attribution License, which permits unrestricted use, distribution, and reproduction in any medium, provided the original work is properly cited.

\begin{abstract}
Corrosion of buried steel pipe is a permanent engineering problem and, albeit the counter measures against degradation, when the corrosion process takes place, the damage has costly impact. In order to study the corrosion behavior of pipelines, it is possible to use actual soil extracts or simulated soil solutions. The extract is much related to specific sites and consequently too strict to permit a general understanding. The simulated soil presents, as advantage, its inorganic characteristic and easy preparation. In this paper, we present some theoretical results concerning the chemical equilibria of NS1, NS2, NS3, and NS4 simulated soil solutions. Besides, we have studied the effect of the above four media in corrosion behavior and polarization curves were performed for an API 5L X65 steel. The theoretical findings show that each ionic concentration varies for a 6-12 pH range. The experimental data suggested that the corrosion currents decrease as high is the $\mathrm{pH}$ and increase as high is the chloride content. Notwithstanding these facts, for multielectrolyte solutions, a simple correlation with a given ion is not straightforward but the complementary approaches used here give useful insights.
\end{abstract}

\section{Introduction}

Carbon steels of buried pipelines are susceptible to degradation by soil corrosivity. Therefore, this situation causes worldwide safety and economy concerns. The uses of coating and cathodic protection are the standard procedures. However, during in-service period, this coating can suffer localized failures and the steel is exposed to a corrosive environment. Generally, the degradation occurs as transgranular or intergranular stress corrosion cracking or even as hydrogen embrittlement in carbon dioxide environment because of mechanical stress. Few works are devoted to investigate corrosion processes caused by aqueous solutions without carbon dioxide. In this sense, marked reductions in area were observed near corrosion potentials of API 5L X65 when performed in slow strain rate test [1]. This fact shows that, even without $\mathrm{CO}_{2}$, the corrosion behavior close to free potential is related to stress corrosion cracking.

To study the corrosivity of soil environments by ordinary electrochemical methods, two media are frequently usedextract solution from soil samples and simulated ones. The first option is very complex because it can contain, besides inorganic species, organic chemicals and even bacteria. Albeit their high correlation with the site where the pipe is buried, its use is not applied everywhere precisely because of inherent local characteristics. Then, the simulated ones are used mainly due to their reproducibility in laboratory [1]. We can cite several synthetic solutions [2-4] proposed to meet this requirement. These synthetic solutions frequently provoke stress corrosion cracking and are widespread used to evaluate cracking susceptibility of pipeline steels. Even with this effectiveness, little attention is devoted to the solution itself, such as that present in the papers of Sun et al. [5] and Zhang and Cheng [6].

The majority of papers deal with the presence of carbon dioxide frequently produced by decaying organic matter present in soil. Indeed, this environment is prone to promote corrosion process [7] but some embrittlement was also detected for pipeline steel X65 in slow strain rate test without bubbling carbon dioxide [2].

The stress corrosion of carbon steel depends on $\mathrm{pH}$ and carbonate-bicarbonate equilibrium because ferrous ions 
interact with these species. Thus, we have chosen the synthetic solutions named NS1, NS2, NS3, and NS4 with the compositions described by Xue and Cheng [2]. The bicarbonate ion is believed to play a dominant role in iron dissolution [8], at least for the initial stages. In spite of the prime importance of pipeline corrosion, the knowing of bicarbonate content in synthetic solution such as NS for a $\mathrm{pH}$ range of engineering interest is rare. Indeed, the investigation of chemical equilibria is one of the objectives of the present paper, besides the determination of corrosion current density in aerated and deaerated conditions. Thus, in the present work, we have calculated the chemical equilibria of all species for the four solutions and performed polarization curves to evaluate the corrosion resistance of API 5L X65 in these media.

\section{Methods and Materials}

2.1. Computational Simulations. In this work, we used a computational tool (home-developed software in SCILAB 5.3 language, (c) INRIA-ENPC) in order to determine the concentrations of all species in aqueous equilibrium. This program solves, iteratively, a large nonlinear system of algebraic equations, which represents chemical equilibrium relationships, material balances, and $\mathrm{pH}$ specification.

Activity coefficients $\left(\gamma_{i}\right)$ for electrically charged species were calculated considering long-range interactions only, using extended Debye-Hückel model, as follows:

$$
\log \left(\gamma_{i}\right)=-\frac{z_{i}^{2} A I^{1 / 2}}{1+B a I^{1 / 2}},
$$

where $a$ is the ionic radius, $z_{i}$ is the charge of ion $i, I$ represents the ionic force, and

$$
A=1.82 \times 10^{6}(\varepsilon T)^{3 / 2} .
$$

In (2), $\varepsilon$ is the dielectric constant of water at $298.15 \mathrm{~K}$ and $T$ is the absolute temperature (Kelvin). We also considered, in (1), the product $B a \cong 1.5$, as suggested by Glinkina et al. [9] and recommended by IUPAC (Bates-Guggenhein convention for chloride ion). This approximation is valid when the ionic force is lesser than $0.2 \mathrm{~mol} / \mathrm{L}$. Ionic force is calculated by the expression

$$
I=\frac{1}{2} \sum_{i} z_{i}^{2} C_{i},
$$

where $C_{i}$ is the molar concentration (in $\mathrm{mol} / \mathrm{L}$ ) of ion $i$. Thus, with the values for molar concentrations, we can calculate the ionic force for the solutions NS1, NS2, NS3, and NS4. However, these concentrations are not known, a priori, and were calculated by solving a nonlinear system of algebraic equations. The activity for each species is evaluated as $a_{i}=$ $\gamma_{i} C_{i}$.

In this work, we considered the following chemical equilibria in aqueous phase:

(a) Water equilibrium:

$$
\mathrm{H}^{+}+\mathrm{OH}^{-} \Longleftrightarrow \mathrm{H}_{2} \mathrm{O}
$$

(b) Calcium ion equilibria:

$$
\begin{gathered}
\mathrm{Ca}^{2+}+\mathrm{OH}^{-} \Longleftrightarrow \mathrm{CaOH}^{+} \\
\mathrm{Ca}^{2+}+\mathrm{CO}_{3}^{2-} \Longleftrightarrow \mathrm{CaCO}_{3} \quad \text { (aq) } \\
\mathrm{Ca}^{2+}+\mathrm{HCO}_{3}^{-} \Longleftrightarrow \mathrm{CaHCO}_{3}^{+}
\end{gathered}
$$

(c) Magnesium ion equilibria:

$$
\begin{gathered}
\mathrm{Mg}^{2+}+\mathrm{OH}^{-} \Longleftrightarrow \mathrm{MgOH}^{+} \\
\mathrm{Mg}^{2+}+\mathrm{CO}_{3}{ }^{2-} \Longleftrightarrow \mathrm{MgCO}_{3} \quad(\mathrm{aq}) \\
\mathrm{Mg}^{2+}+\mathrm{HCO}_{3}{ }^{-} \Longleftrightarrow \mathrm{MgHCO}_{3}{ }^{+}
\end{gathered}
$$

(d) Carbonate/bicarbonate equilibrium:

$$
\mathrm{HCO}_{3}{ }^{-} \Leftrightarrow \mathrm{H}^{+}+\mathrm{CO}_{3}{ }^{2-}
$$

(e) Sulfuric acid dissociation:

$$
\begin{aligned}
& \mathrm{H}_{2} \mathrm{SO}_{4} \Leftrightarrow \mathrm{HSO}_{4}{ }^{-}+\mathrm{H}^{+} \\
& \mathrm{HSO}_{4}{ }^{-} \Longleftrightarrow \mathrm{SO}_{4}{ }^{2-}+\mathrm{H}^{+}
\end{aligned}
$$

(f) Carbon material balance:

$$
\begin{aligned}
{[\mathrm{C}]_{\mathrm{TOT}}=} & {\left[\mathrm{CO}_{3}{ }^{2-}\right]+\left[\mathrm{HCO}_{3}{ }^{-}\right] } \\
& +\left[\mathrm{CaCO}_{3}\right]+\left[\mathrm{CaHCO}_{3}{ }^{+}\right]+\left[\mathrm{MgCO}_{3}\right] \\
& +\left[\mathrm{MgHCO}_{3}{ }^{+}\right]
\end{aligned}
$$

(g) Calcium material balance:

$$
\begin{aligned}
{[\mathrm{Ca}]_{\mathrm{TOT}}=} & {\left[\mathrm{Ca}^{2+}\right]+\left[\mathrm{CaOH}^{+}\right] } \\
& +\left[\mathrm{CaCO}_{3}\right]+\left[\mathrm{CaHCO}_{3}^{+}\right]
\end{aligned}
$$

(h) Magnesium material balance:

$$
\begin{aligned}
{[\mathrm{Mg}]_{\mathrm{TOT}}=} & {\left[\mathrm{Mg}^{2+}\right]+\left[\mathrm{MgOH}^{+}\right] } \\
& +\left[\mathrm{MgCO}_{3}\right]+\left[\mathrm{MgHCO}_{3}^{+}\right]
\end{aligned}
$$

(i) Sulfur material balance:

$$
[\mathrm{S}]_{\mathrm{TOT}}=\left[\mathrm{SO}_{4}{ }^{2-}\right]+\left[\mathrm{HSO}_{4}{ }^{-}\right]+\left[\mathrm{H}_{2} \mathrm{SO}_{4}\right]
$$

The nonlinear system of algebraic equations is solved in order to evaluate all concentrations (and activities) for the chemical species in solution. The nonlinear system has 14 equations and 15 variables (concentrations) to be determined as follows: $\left[\mathrm{CO}_{3}{ }^{2-}\right],\left[\mathrm{HCO}_{3}{ }^{-}\right],\left[\mathrm{CaCO}_{3}\right],\left[\mathrm{CaHCO}_{3}{ }^{+}\right]$,

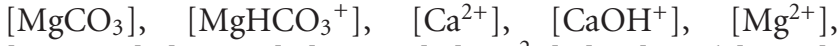
$\left[\mathrm{MgOH}^{+}\right],\left[\mathrm{H}_{2} \mathrm{SO}_{4}\right],\left[\mathrm{HSO}_{4}{ }^{-}\right],\left[\mathrm{SO}_{4}{ }^{2-}\right],\left[\mathrm{H}^{+}\right]$, and $\left[\mathrm{OH}^{-}\right]$. Thus, with a $\mathrm{pH}$ specification the mathematical problem can be solved. Other specifications were possible, such as carbon 
TABLE 1: Composition of simulated soil solutions [1].

\begin{tabular}{lcccc}
\hline & \multicolumn{4}{c}{ Composition (g/L) } \\
Reagents & NS1 & NS2 & NS3 & NS4 \\
\hline $\mathrm{KCl}$ & 0.149 & 0.142 & 0.037 & 0.122 \\
$\mathrm{NaHCO}_{3}$ & 0.504 & 1.031 & 0.559 & 0.483 \\
$\mathrm{CaCl}_{2} \cdot 2 \mathrm{H}_{2} \mathrm{O}$ & 0.159 & 0.073 & 0.008 & 0.181 \\
$\mathrm{MgSO}_{4} \cdot 7 \mathrm{H}_{2} \mathrm{O}$ & 0.106 & 0.254 & 0.089 & 0.131 \\
\hline
\end{tabular}

dioxide partial pressure, in systems with carbon dioxide, obtaining the other variables as dependant ones.

The nonlinear system represented by (4)-(17) and by $\mathrm{pH}$ specification was numerically solved using a damped Newton's method with a norm-reduction strategy (in order to avoid convergence problems). This strategy is necessary since this nonlinear system shows some convergence problems $[10,11]$.

One can note that inert ions, as chloride, do not take part in equilibrium reactions, but their higher concentrations affect the solution ionic force (see (3)). The equilibrium constants for the above reactions are found elsewhere [9].

2.2. Materials and Experimental Procedures. The samples were made from pipeline material API 5L X65 steel. The optical metallography of as-received steel is shown in Figure 2. The samples have dimension of $10 \mathrm{~mm} \times 10 \mathrm{~mm}$ and the sides were coated by epoxy resin. The working surfaces were ground with emery paper up to $\# 600$, rinsed with distilled water, and dried with hot air before immersion in the electrolyte.

The solutions were prepared with analytical chemicals and the compositions are equal to those used in theoretical studies. These compositions were proposed by Parkins et al. [1] and are showed in Table 1. In the cases of deaerated tests, the electrolytes were bubbled with pure $\mathrm{N}_{2}$ for previous $30 \mathrm{~min}$ and during all electrochemical tests. The open circuit potential (OCP) is in the interval $[-0.8,-0.7]$ $V_{\text {sce }}$ (saturated calomel electrode), reached a steady-state condition after $5.0 \mathrm{ks}$. All polarization tests were performed at scan rate of $1.0 \mathrm{mV} / \mathrm{s}$ from $0.3 \mathrm{~V}$ below corrosion potential up to $1.0 V_{\text {sce. }}$. The corrosion current density was evaluated using a Stern-Gear procedure [12] by using the software of VERSASTAT 3-400 potentiostat. The tests were conducted at room temperature.

\section{Results and Discussion}

Figures 1 and 2 present the calculated concentrations, respectively, for carbonate and bicarbonate ions in solutions NS1, NS2, NS3, and NS4. An analysis of Figure 1 clearly shows an increasing concentration of carbonate ion with $\mathrm{pH}$. This result is expected, considering the bicarbonate dissociation reaction at high $\mathrm{pH}$. On the other hand, bicarbonate concentration presents a decreasing evolution as $\mathrm{pH}$ increases. One can note that, at $\mathrm{pH}$ above 8 , all inorganic carbon remains as bicarbonate. The NS2 solution has the high level of carbonate amongst them. The bicarbonate content behaves inversely to carbonate; that is, it decreases steadily for solutions

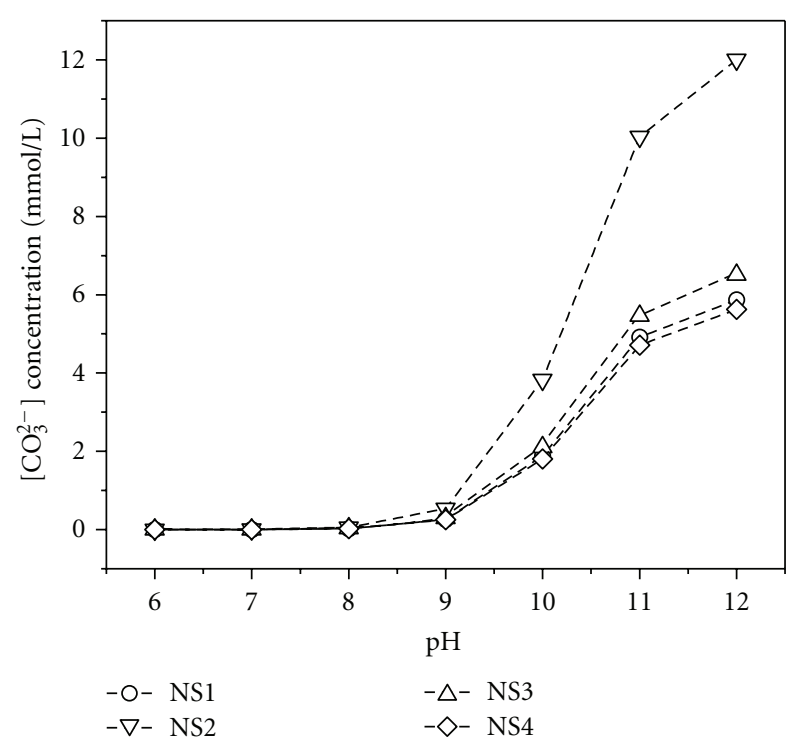

FIgURE 1: Carbonate concentration for NS1-4 solutions.

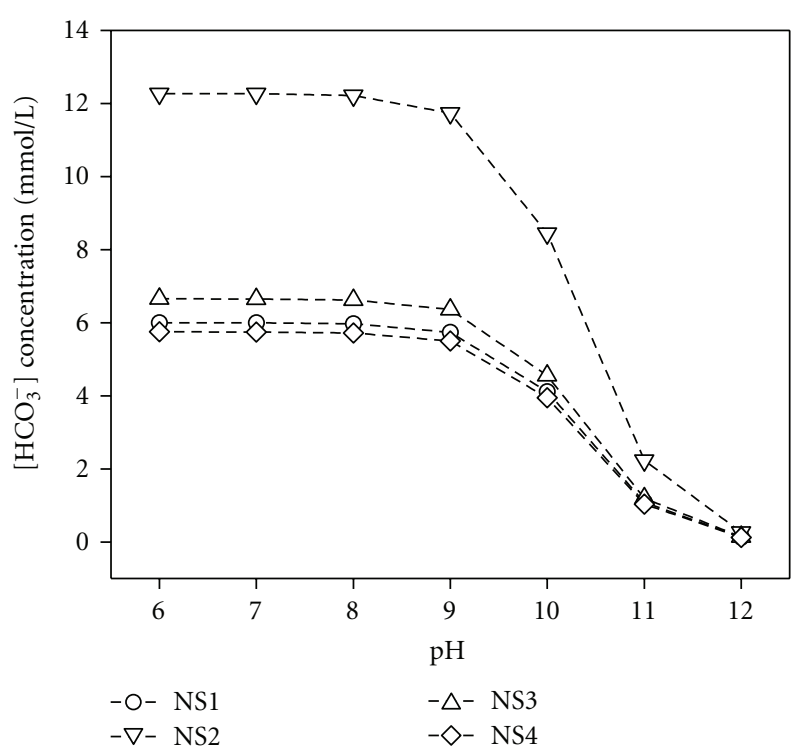

FIgURE 2: Bicarbonate concentration for NS1-4 solutions.

above $\mathrm{pH}$ 8, as shown in Figure 2. As expected, the NS2 presents the higher content of bicarbonate, as consequence of $1.031 \mathrm{~g} / \mathrm{L}$ of $\mathrm{NaHCO}_{3}$ of original composition. These profiles can be useful to evaluate, for the $\mathrm{pH}$ range of interest, all concentrations in solution.

The chloride ion does not react with any species in the electrolyte model, and then all chloride is present as dissolved ion, regardless of salt. However, it significantly affects the ionic strength and changes the equilibria as given by (3) and (1), even remaining as a nonreactive ion. This consideration does not mean that chloride is effectless in corrosion process. The solutions NS1 and NS4 have almost the same high quantity of chloride, around $5 \mathrm{mmol} / \mathrm{L}$. As to sulphate, we also observed a constant content in the $\mathrm{pH}$ range $6-12$, due to another reason. The sulphate shows a double dissociation, 


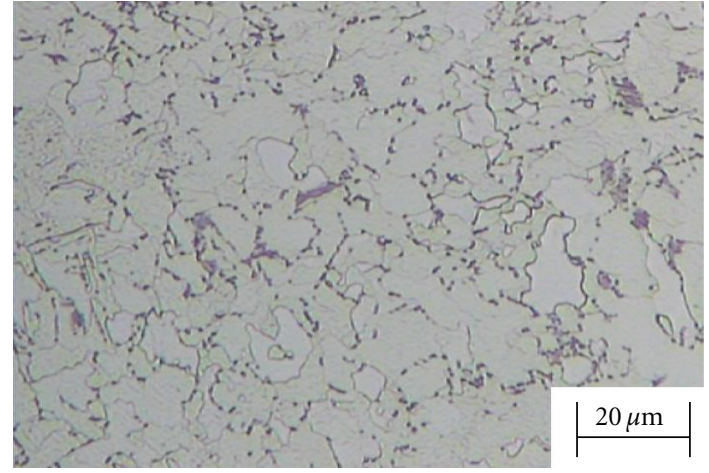

Figure 3: Microstructure of API 5L X65.

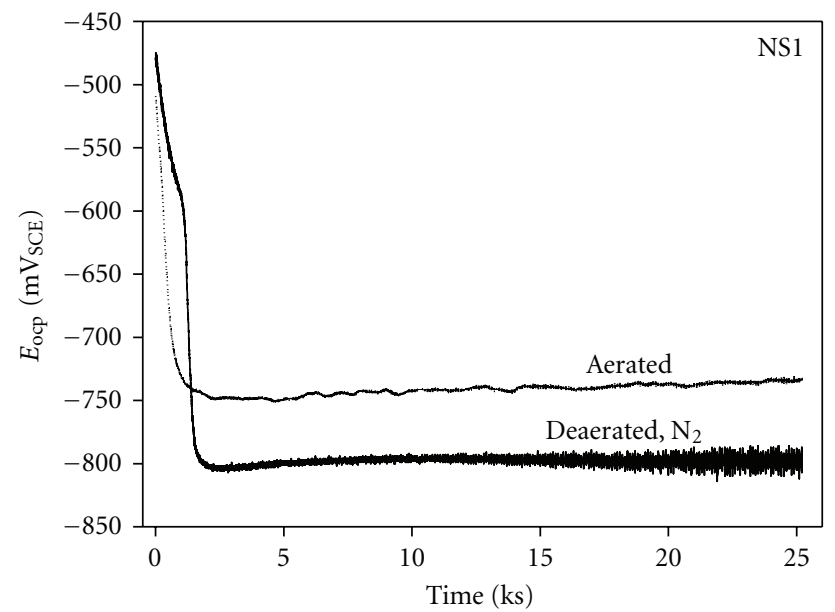

FIGURE 4: Free corrosion potential evolution for NS1 solution.

accordingly to (11)-(12), that is already completed for a $\mathrm{pH}$ above 6; then in 6-12 $\mathrm{pH}$ range, the sulfate concentration does not vary at all.

With a simulation of ion contents for all solution, we performed the polarization curves of API 51 X65 steel. This steel is largely used as material for pipeline buried structure. An optical microscopy of this steel showed a ferritic-pearlitic microstructure of steel as depicted in Figure 3. When the surface is protecting by cathodic protection, the interfacial $\mathrm{pH}$ is close to 11 due to the alkalinization of reduction reactions, and without this protection, the $\mathrm{pH}$ is near neutrality $[2,7]$. In both cases there are corrosion problems related to soil corrosivity. In the present paper, we have chosen to study the solution with and without deaeration. The open circuit potential for all solutions, in aerated and deaerated conditions, presents a similar behavior depicted in Figure 4 for NS1. The stable potential is reached after circa $3 \mathrm{ks}$; thus, all polarization curves were carried out at $5.0 \mathrm{ks}$, when the steady-state condition has occurred. For the sake of concision, we only show one potential-time curve since the others are very similar. In general, the deaerated solutions produce open circuit potentials more negative in approximately $50 \mathrm{mV}$.

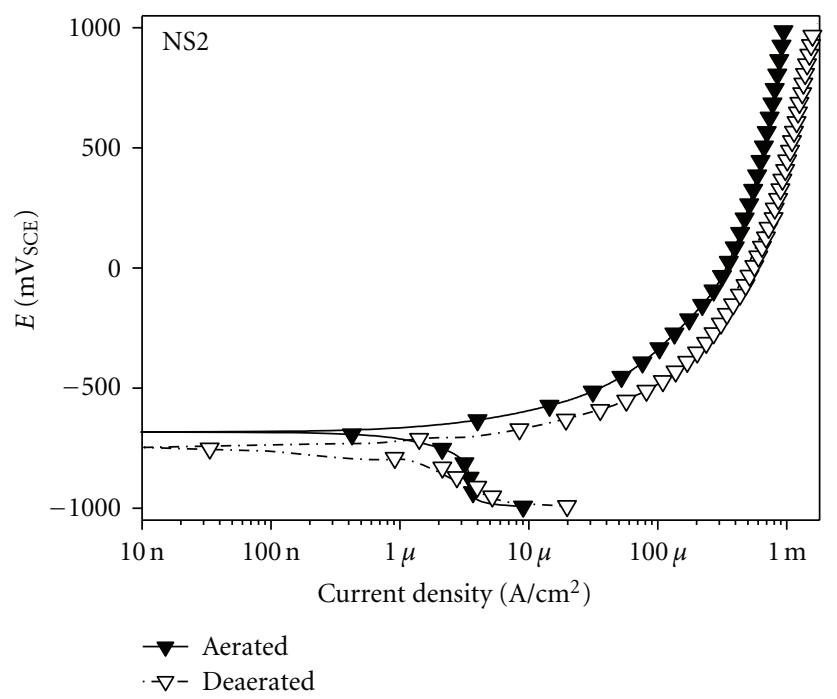

FIgURE 5: Polarization curves for NS2 solution.

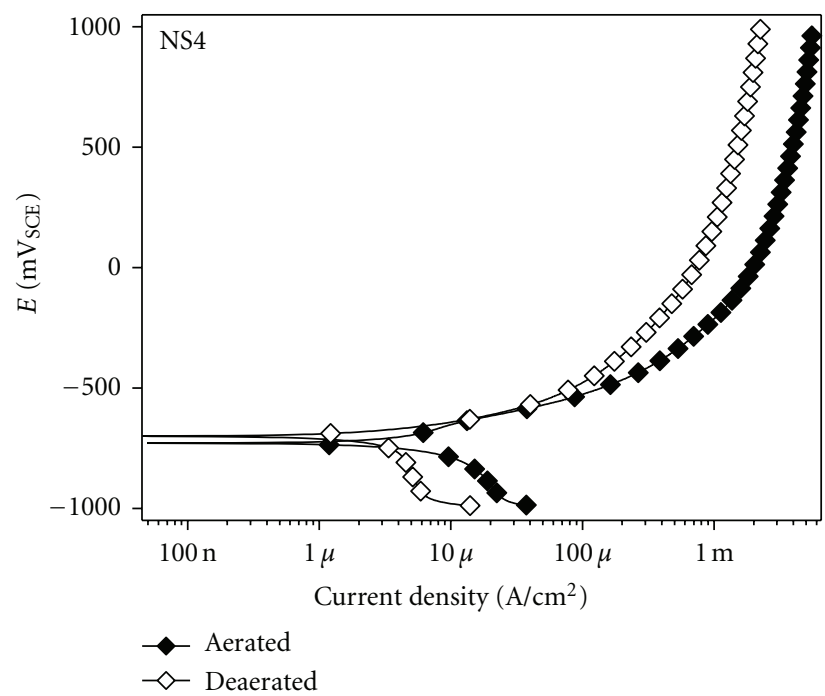

FIgURE 6: Polarization curves for NS4 solution.

Polarization curves were performed after $5.0 \mathrm{ks}$ at open circuit potential (Figures 5 and 6 ). The polarization curves for all solutions are similar with respect to dissolution behavior; thus, we only show results of NS2 and NS4. The anodic branches present a uniform dissolution above corrosion potential. The cathodic currents are dependent of deaeration conditions because of oxygen availability at reduction reaction. Therefore, high current density occurs for aerated electrolytes, as clearly shown in Figure 6. The aeration also affects the characteristic of oxide formed. All these facts affect the global reactions and the corrosion current densities obtained from these experiments are influenced by media and aeration conditions. The current corrosion densities are depicted in Figure 7 and, indeed, the aerated solutions is more corrosive than deaerated ones.

The actual pH of each solution can be seen in Figure 7, in addition to the corrosion current density. All measured $\mathrm{pHs}$ 


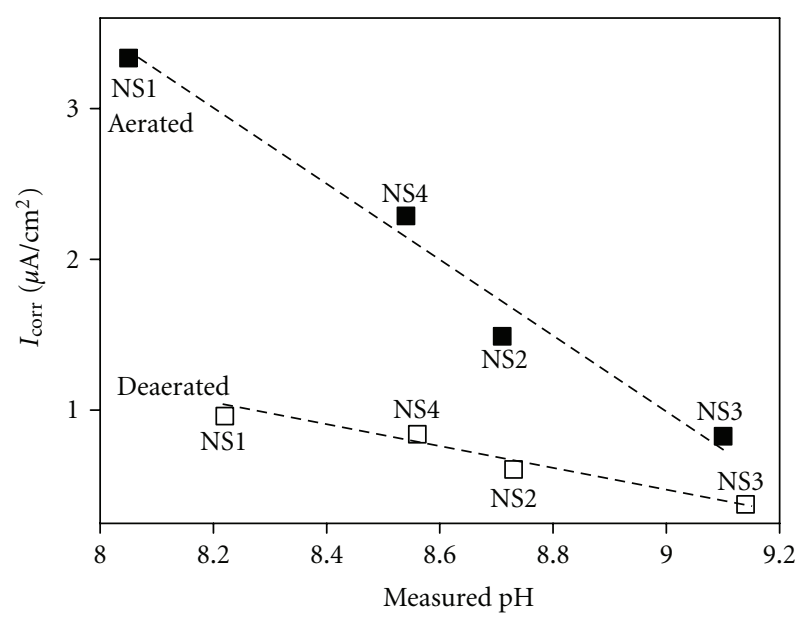

FIGURE 7: Effects of actual pH on corrosion current density. Straight lines are plotted as a guide to the eyes.

of fresh solutions are in the range $8.1 \leq \mathrm{pH} \leq 9.2$, that is, alkaline media. Moreover, the deaerated solutions are slightly more alkaline than aerated ones. Karagianni and Avranas [13] also observed this alkalinization in aqueous solution bubbled with nitrogen gas, due to carbon dioxide removing by nitrogen. Therefore, the formation of carbonic acid is not favorable. All modeled results can be considered as being a deaerated condition since the oxygen does not taken into account in the equilibria.

The localization of measured $\mathrm{pH}$ and open corrosion potential in aqueous Eh-pH diagram indicates that the majority of samples are located above the line of hydrogen evolution, and some are slightly below but with low overpotential. Consequently, the cathodic process related to oxygen is the most important and the $\mathrm{N}_{2}$ purging is effective in reducing the corrosion current, as observed in Figure 7. In other words, the aerated electrolytes present higher corrosion current densities than deaerated ones because the oxygen reduction is the main cathodic process, or even the only one. Moreover, also there is a dependence of corrosion current with the actual $\mathrm{pH}$. Indeed, as $\mathrm{pH}$ increases, we note a decreasing of corrosion current, in spite of differences in electrolyte compositions. For iron in pure water, the significative reduction of corrosion with $\mathrm{pH}$ takes place above $\mathrm{pH}$ 10; however, in the present case, this trendiness is observed just above $\mathrm{pH}$ 8. Probably this behavior can be ascribed to the dissociation of bicarbonate as noted in Figure 2. Results from Parkins and Zhou [7], related to cracking of carbon steel in soil solutions, showed that the dissolution-driven crack growth rate increases as bicarbonate does. In the present work, a similar correlation of bicarbonate content and corrosion current is suggested to be also dependent on chloride. Indeed, in multielectrolyte solution, as is the case for NS electrolytes, a simple dependency of any factor is rare. Inasmuch as these facts, a more probable correlation amongst all solutions and corrosion current density was found for the chloride concentration and actual $\mathrm{pH}$, as shown in Figure 7. From the experimental results, it is possible to found that the chloride affects more than simply the ionic force, since it activates the surface.

The research in progress intends to consider the $\mathrm{CO}_{2}$ gas and the stability of iron scales in these environments. The goal is the determination of the minimum content of iron enough to stabilize specific compounds such as $\mathrm{FeCO}_{3}$, $\mathrm{Fe}_{3} \mathrm{O}_{4}$, and $\mathrm{Fe}(\mathrm{OH})_{2}$ that is believed to be related to the onset of cracking. Anyway, an orthogonal design of experiment could be useful to reveal the real effect of each species, but, unfortunately, it is not possible to obtain with the usual simulated soil solutions such as NS1-4 used here and elsewhere [2].

\section{Conclusions}

Some theoretical results of chemical equilibria for NS1, NS2, NS3, and NS4 simulated soil solutions were done. The ionic effect of all species was computed by using a Debye-Hückel approach to evaluate all activities and concentrations. From these data, the profiles of each ion were available for the 6-12 $\mathrm{pH}$ range. This kind of result is important because the soil can exhibit the same compounds but different $\mathrm{pH}$ values. In this sense, the equilibrium conditions can modify significantly the ion availability for a small hydrogen ionic variation, for example, for bicarbonate at $\mathrm{pH} 9.0$ and 9.5 the reduction is of approximately $15 \%$ for NS2 solution. The corrosion current density of API 5L X65 indicates that the deaerated media reduce the corrosion intensity as a direct consequence of oxygen cathodic reaction. Moreover, with respect of corrosion current density, the higher corrosion observed in NS1 and NS4 multielectrolyte media is probably related to the content of chloride.

\section{Acknowledgments}

The authors acknowledge the financial support of the Brazilian agencies $\mathrm{CNPq}$, CAPES, FAPERJ, and ProCiencia grants of UERJ. The authors also would like to thank the Apolo Company for the cession of steel.

\section{References}

[1] R. N. Parkins, W. K. Blanchard Jr, and B. S. Delanty, "Transgranular stress corrosion cracking of high-pressure pipelines in contact with solutions of near neutral pH," Corrosion, vol. 50, no. 5, pp. 394-408, 1994.

[2] H. B. Xue and Y. F. Cheng, "Electrochemical corrosion behavior of X80 pipeline steel in a near-neutral $\mathrm{pH}$ solution," Materials and Corrosion, vol. 61, no. 9, pp. 756-761, 2010.

[3] Z. Liu, G. Zhai, X. Li, and C. Du, "Effect of deteriorated microstructures on stress corrosion cracking of X70 pipeline steel in acidic soil environment," Journal of University of Science and Technology Beijing, vol. 15, no. 6, pp. 707-713, 2008.

[4] P. Liang, C. W. Du, X. G. Li, X. Chen, and Z. liang, "Effect of hydrogen on the stress corrosion cracking behavior of X80 pipeline steel in Ku'erle soil simulated solution," International Journal of Minerals, Metallurgy and Materials, vol. 16, no. 4, pp. 407-413, 2009.

[5] W. Sun, S. Nešić, and R. C. Woollam, "The effect of temperature and ionic strength on iron carbonate $\left(\mathrm{FeCO}_{3}\right)$ 
solubility limit," Corrosion Science, vol. 51, no. 6, pp. 12731276, 2009.

[6] G. A. Zhang and Y. F. Cheng, "On the fundamentals of electrochemical corrosion of X65 steel in $\mathrm{CO}_{2}$-containing formation water in the presence of acetic acid in petroleum production," Corrosion Science, vol. 51, no. 1, pp. 87-94, 2009.

[7] R. N. Parkins and S. Zhou, "The stress corrosion cracking of C-Mn steel in $\mathrm{CO}_{2}-\mathrm{HCO}_{3}^{-}-\mathrm{CO}_{3}^{2-}$ solutions. II: electrochemical and other data," Corrosion Science, vol. 39, no. 1, pp. 175-191, 1997.

[8] B. R. Linter and G. T. Burstein, "Reactions of pipeline steels in carbon dioxide solutions," Corrosion Science, vol. 41, no. 1, pp. 117-139, 1999.

[9] I. V. Glinkina, V. A. Durov, and G. A. Mel'nitchenko, "Modelling of electrolyte mixtures with application to chemical equilibria in mixtures-prototypes of blood's plasma and calcification of soft tissues," Journal of Molecular Liquids, vol. 110, no. 1-3, pp. 63-67, 2004.

[10] H. R. Yeager and R. W. Dutton, "Improvement in norm-reducing Newton methods for circuit simulation," IEEE Transactions on Computer-Aided Design of Integrated Circuits and Systems, vol. 8, no. 5, pp. 538-546, 1989.

[11] E. Ngoya, J. Roussel, and J. J. Obregon, "Newton-Raphson iteration speed-up algorithm for the solution of nonlinear circuit equations in general-purpose CAD programs," IEEE Transactions on Computer-Aided Design of Integrated Circuits and Systems, vol. 16, no. 6, pp. 638-644, 1997.

[12] M. Stern and A. L. Geary, "Electrochemical polarization: I. A theoretical analysis of the shape of polarization curves," Journal of the Electrochemical Society, vol. 104, no. 1, pp. 56-63, 1957.

[13] M. Karagianni and A. Avranas, "The effect of deaeration on the surface tension of water and some other liquids," Colloids and Surfaces A, vol. 335, no. 1-3, pp. 168-173, 2009. 

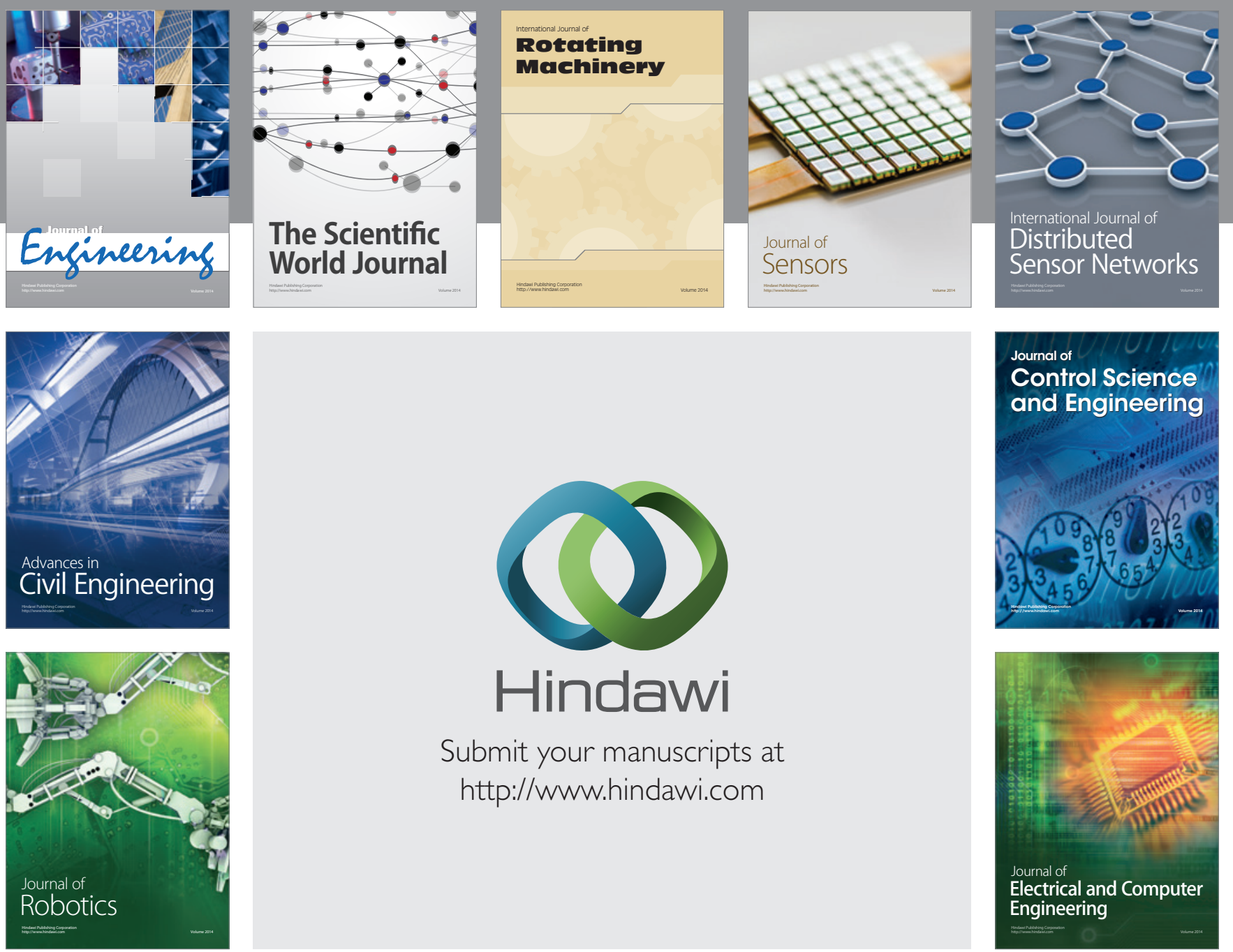

Submit your manuscripts at

http://www.hindawi.com
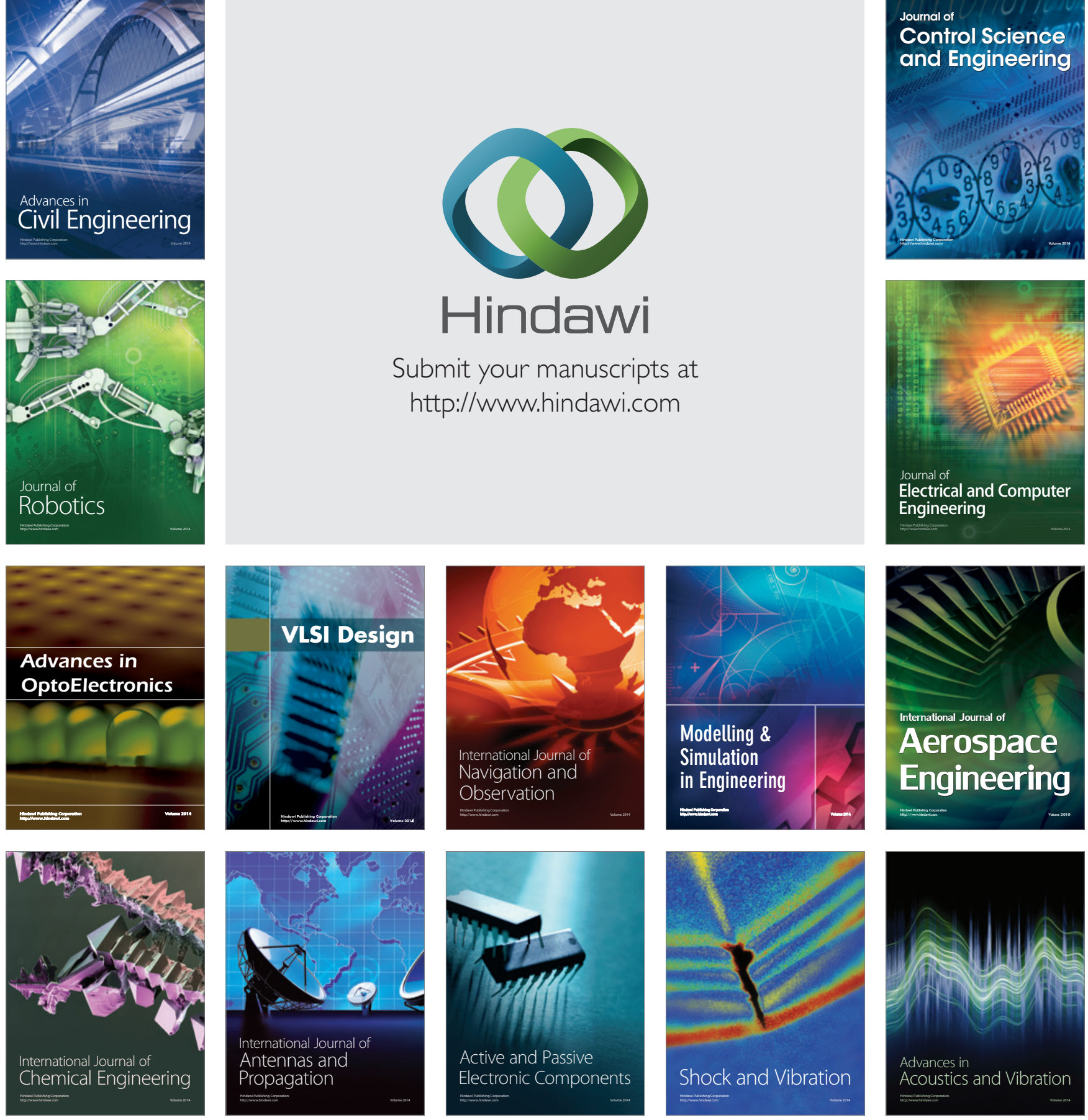